\title{
ESTRUTURA TERMOHALINA DO LITORAL CENTRO-NORTE CATARINENSE
}

\author{
CARVALHO, J.L.B.; SCHETTINI, C.A.F. \& T.M. RIBAS \\ Universidade do Vale do Itajaí - CTTMar \\ Rua Uruguai, 458, Itajaí-SC, 88.302-202 \\ carvalho@univali.rct-sc.br
}

\begin{abstract}
RESUMO
Este trabalho apresenta a descrição do comportamento sazonal das massas d'água que ocorrem na região interna da Plataforma Continental do Sudeste do Brasil, especificamente sobre o Litoral Centro Norte Catarinense (LCNC). O LCNC está localizado entre o rio Itapocu, Barra Velha, e a Baía de Tijucas. Dentro de seus domínios encontram-se a Reserva Marinha do Arvoredo que abriga uma grande diversidade biológica e o rio Itajaí, o maior rio do Estado que desemboca no Atlântico. Foram realizados quatro cruzeiros oceanográficos no LCNC entre novembro de 94 e julho de 95 nos quais foram obtidas informações de temperatura e salinidade com STD. Foram utilizadas também informações de vento simultâneos às campanhas obtidos numa plataforma de petróleo que opera ao largo de Itajaí a 100 milhas da costa. Os resultados evidenciaram dois padrões sazonais distintos bastante influenciados pelo vento: o de primavera-verão, quando a coluna d'água se encontra muito estratificada podendo haver eventos de ressurgência pela ação dos ventos provindos do quadrante norte e subsidência junto a costa pela ação de ventos de sul; o de outono-inverno, quando a coluna d'água se encontra mais homogênea devido à ação e subsidência costeira ou pela advecção de águas de origem subantártica para dentro da região.
\end{abstract}

Palavras chave: Salinidade, Temperatura, Massas D'água, Litoral de Santa Catarina

\section{TERMOHALINE STRUCTURE OF SANTA CATARINA NORTH COAST.}

\begin{abstract}
This paper describes the seasonal behavior of the water masses which occur inside the South Brazilian Bight, specifically inside the Santa Catarina Center-North Inner shelf. It is located between the Itapocu river and the Tijucas Bay. Inside the area there is the Marine Reserve of Arvoredo and the Itajaí river, the most important river of the State that reachs the Atlantic Ocean. Four surveys cruises was done since November 94 to July 95 making STD measurements. Wind data was obtained at an oil platform located 100 nautical miles off Itajaí city. During spring and summer the water columns was stratified and upwelling and doweling events occur according to the northern and southern winds. During autumn-winter period the water column was homogeneous because of doweling or advection of modified subantartic water trough the area.
\end{abstract}

Keywords: Salinity, Terperature, Water Masses, Santa Catarina Coast

\section{INTRODUÇÃO}

O propósito principal deste trabalho é contribuir para o conhecimento da estrutura oceanográfica do litoral Centro Norte de Santa
Catarina afim de subsidiar atividades de gerenciamento costeiro.

As escalas temporal e espacial foram estabelecidas de maneira a possibilitar a visualização detalhada da influência do aporte

\footnotetext{
*Projeto financiado com recursos da Fundação Banco do Brasil
} 
continental sobre a região costeira e do comportamento das massas de água que ocorrem na região, no que diz respeito à mistura, estratificação, ressurgência, variabilidade sazonal, etc.

O Litoral Centro Norte Catarinense (LCNC) compreende a faixa marinha entre o Rio Itapocu no município de Barra Velha e a Baía de Tijucas, no município de mesmo nome. Este encontra-se inserido na Plataforma Continental Sudeste do Brasil (PCSE), segundo segmentação do litoral brasileiro proposta por Castro, 1990. A PCSE (Fig. 1) é limitada ao norte pelo Cabo Frio (23 $\mathrm{S})$, ao sul pelo Cabo de Santa Marta Grande (28 40'S), a oeste pela linha de costa e a leste pela quebra da plataforma localizada em profundidades variando entre 120 e 180 metros (Castro, 1990). A orientação geral da linha de costa é NE-SW, mas em toda a porção referente ao litoral catarinense a mesma assume a direção N-S.

Uma das principais características da PCSE é a pequena influência direta do aporte continental, uma vez que os grandes rios da Região Sul do Brasil afluem para a Bacia do Prata. Os três maiores rios do LCNC possuem vazões médias pouco superiores a 50 $\mathrm{m}^{3} / \mathrm{s}$ : o rio Itajaí $\left(247 \mathrm{~m}^{3} / \mathrm{s}\right)$, o Rio Itapocu (77

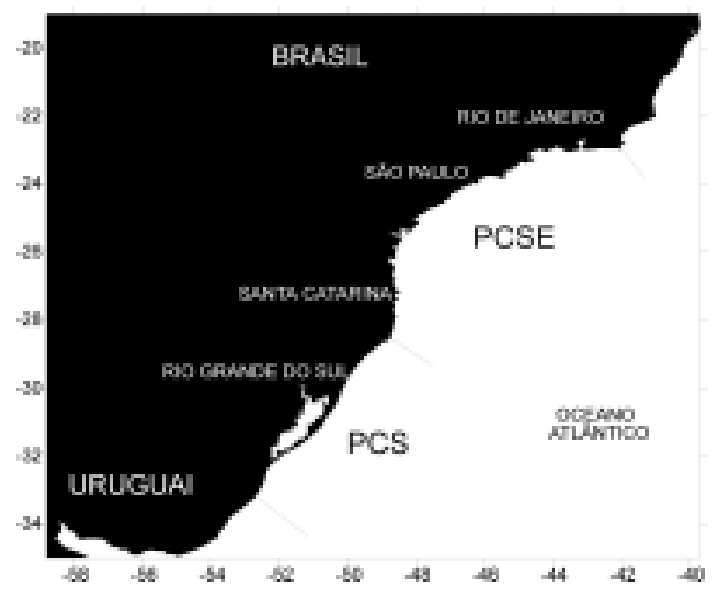

Fig. 1 - Localização do Litoral Centro Norte Cantarinense. $\mathrm{m}^{3} / \mathrm{s}$ ) e o Tijucas (58 $\mathrm{m}^{3} / \mathrm{s}$ ) (Schettini et al, 1996). Em épocas de grande pluviosidade os picos de descarga podem aumentar significativamente $\left(5180 \mathrm{~m}^{3} / \mathrm{s}\right.$ em 1957 e $4.900 \mathrm{~m}^{3} /$ s em1984 no Rio Itajaí) (INPH, 1985).

Ao sul da área de estudo encontra-se a Reserva Marinha do Arvoredo (REBIO Arvoredo) que compreende um arquipélago rochoso composto por três ilhas: Arvoredo, Deserta e Galés; e ainda o Calhau de São Pedro. A região abriga uma grande diversidade biológica de interesses econômico como clupeídeos, engraulídeos (Rodrigues-Ribeiro et al, 1997) e lulas (Perez et al, 1997) e ecológico de diatomáceas, cianobactérias e dinoflagelados (Rörig et al, 1997), cladóceros, copépodos, larvas de decápodas, salpas, ovos e larvas de engraulídeos e clupeídeos (Rodrigues Ribeiro, 1997), algas calcáreas (Reuss-Strenzel et al, 1987), e outros. A necessidade de preservação desta diversidade ecológica aliada às evidências anteriores de fenômenos de ressurgência da Água Central do Atlântico Sul (ACAS) sobre a PCSE, e provavelmente também sobre os domínios da reserva, motivaram a adequação da malha de amostragem para identificar e monitorar a sazonalidade dos fenômenos oceanográficos que ali ocorrem.

A estrutura oceanográfica da PCSE foi estudada inicialmente por Emilson (1961). Este classificou as massas d'água que ocorrem na região como Água Tropical (AT) $\left(\mathrm{T}>20.0{ }^{\circ} \mathrm{C}\right.$ e $\left.\mathrm{S}>36.40\right)$ que é transportada para o sul pela Corrente do Brasil; Água Costeira (AC), bastante influenciada pelo aporte continental de água doce; Água Subtropical $\left(\mathrm{T}<20.0{ }^{\circ} \mathrm{C}\right.$ e $\left.\mathrm{S}<36.40\right)$, posteriormente redefinida como ACAS, originada na convergência subtropical; e Água da Plataforma (AP), resultante da mistura da ACAS com a AT e AC sobre a PCSE. Matsuura (1986) apresentou um modelo da estrutura oceanográfica de massas d'água para a PCSE baseado em 10 cruzeiros oceanográficos realizados entre 1975 e 1981. Castro (1987) motivado pela constatação da existência de va- 
riações sazonais na distribuição das propriedade físicas, sugeriu que a plataforma continental ao largo de Ubatuba fosse subdividida em Plataforma Interna (PI), limitada pela costa e as isóbatas de 40 e 50 metros, e Plataforma Externa (PE), limitada por estas isóbatas e a quebra da plataforma continental. Na PI a estratificação de salinidade e temperatura apresentam grande variação sazonal. Durante o verão, observa-se uma forte estratificação de densidades em função da penetração da ACAS por sobre a plataforma continental produzindo uma termoclina sazonal bem acentuada, e durante o inverno a coluna d'água é predominantemente homogênea e com temperaturas mais baixas. $\mathrm{Na}$ PE não são observadas variações sazonais significativas.

A Plataforma Continental Sul do Brasil (PCS) estende-se do Cabo de Santa Marta

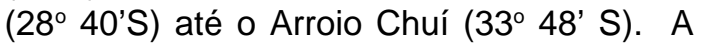
orientação do litoral e as linhas batimétricas seguem regularmente a direção geral SW-NE. A contribuição continental, bastante significativa, é efetuada através da Barra do Rio Grande e mais ao sul pelo Estuário do Rio da Prata. A feição oceanográfica mais importante na PCS é a confluência das correntes do Brasil e Malvinas formando a extremidade oeste da Convergência Subtropical (CS). A CS migra sazonalmente influenciando fortemente a distribuição de massas d'água e circulação na PCS. No inverno, a região é dominada pela Água Subantártica (ASA) $\left(4.0^{\circ} \mathrm{C}<\mathrm{T}<\right.$ $15^{\circ} \mathrm{C}$ e $\left.33.7<\mathrm{S}<34.15\right)$ que se move para o norte devido à ação de correntes costeiras. No verão, a PCS é dominada pela AT que é transportada para o sul pela Corrente do Brasil (Castro, 1998). A ASA, em seu movimento para o norte no inverno, tem sua salinidade reduzida pela contribuição continental. Miranda (1972) apud Miranda (1979) sugeriu que a Água Costeira poderia ser subdividida em Água Costeira com Influência Subantártica (ACISA) $(S<34.0)$, característica do inverno, e Água Costeira com Influência Tropical (ACIT) característica do verão. A penetração desta água fria e pouco salina (ACISA) pela costa sul do Brasil freqüentemente penetra por sobre a PCSE no inverno. Campos et al (1996) apud Castro (1998) constatou uma incursão desta água até $24^{\circ} \mathrm{S}$ no inverno de 1993.

Castro (1990) propõe um modelo conceitual para a circulação gerada pelo vento na PCSE que explica a variação sazonal da estrutura hidrográfica encontrada na PI. Durante o verão, quando se observa uma estratificação acentuada formando duas camadas distintas separadas por uma termoclina sazonal, os ventos predominantes provêm do quadrante N-E. As componentes do vento paralelas à costa são responsáveis pelo transporte da água superficial para mar aberto. A divergência superficial resultante, além de abaixar o nível do mar na costa, induz a ressurgência da ACAS em direção à mesma. O abaixamento do nível do mar cria uma força gradiente horizontal de pressão apontando para a costa. Se houver persistência suficiente do vento (20 horas aproximadamente) a força de gradiente horizontal de pressão entra em equilíbrio com a força de Coriolis resultando numa corrente paralela à costa e no mesmo sentido do vento. Abaixo da termoclina, no entanto, o sentido da corrente se inverteria uma vez que a força gradiente horizontal de pressão apontaria para o sentido contrário, ou seja, para mar aberto. Isto porquê a ressurgência de águas mais densas em direção à costa promoveria a inclinação da termoclina neste sentido intensificando a condição baroclínica e forçando a inversão do gradiente de pressão. Durante o inverno, os ventos predominantes provêm do quadrante S-W. As componentes do vento paralelas à costa agora induzem um transporte do mar aberto em direção à mesma, causando uma convergência superficial costeira e consequentemente a elevação do nível do mar e o afastamento das águas localizadas abaixo da picnoclina. Neste caso, a força de gradiente horizontal de pressão aponta para mar aberto e a corrente paralela 
à costa, resultante do equilíbrio desta com a força de Coriolis, flui no mesmo sentido do vento predominante. Como a coluna d'água estaria homogênea sobre a PI a condição seria barotrópica, ao contrário do verão, não havendo inversão de correntes em profundidade, o que favoreceria a penetração de águas provindas do sul em toda a coluna d'água.

Os mecanismos discutidos acima são o resultado de um equilíbrio dinâmico, evidenciado numa escala sazonal, da ação de eventos sucessivos com escala de tempo menores. A dinâmica de sistemas frontais sobre a PCSE é a principal responsável pelo padrão de ventos dos quadrantes $\mathrm{N}-\mathrm{E}$ e S-W. E como estes eventos ocorrem o ano inteiro com períodos que variam de 6 a 12 dias é de se esperar que os mecanismos de transporte descritos anteriormente ocorram também o ano inteiro, na mesma escala de tempo. O que se observa na realidade é o efeito resultante, ora com o predomínio de uma, ora de outra condição.

\section{MATERIAL DE MÉTODOS}

O presente trabalho foi realizado a partir de informações de salinidade e temperatura obtidos em quatro cruzeiros oceanográficos realizados a bordo do N.Pq. Diadorim entre os anos de 1994 e 1995 durante a execução do "Projeto Integrado da Bacia do Rio Itajaí-Açu e área Costeira Adjacente - Diagnóstico e Avaliação Ambiental". Os cruzeiros oceanográficos foram idealizados de forma a cobrir o Litoral Centro Norte Catarinense até a distância de $8 \mathrm{mn}$ da costa (Fig. 2). Na região da llha do Arvoredo este limite foi expandido para $16 \mathrm{mn}$ com o objetivo de se conhecer os processos oceanográficos que ocorrem na REBIO Arvoredo e entornos. Os cruzeiros ocorreram em 9 a 15 de novembro de 1994, 8 a 13 de fevereiro, 6 a 12 de maio e 8 a 13 de julho de 1995 . Em cada cruzeiro foram efetuadas 63 estações oceanográficas,

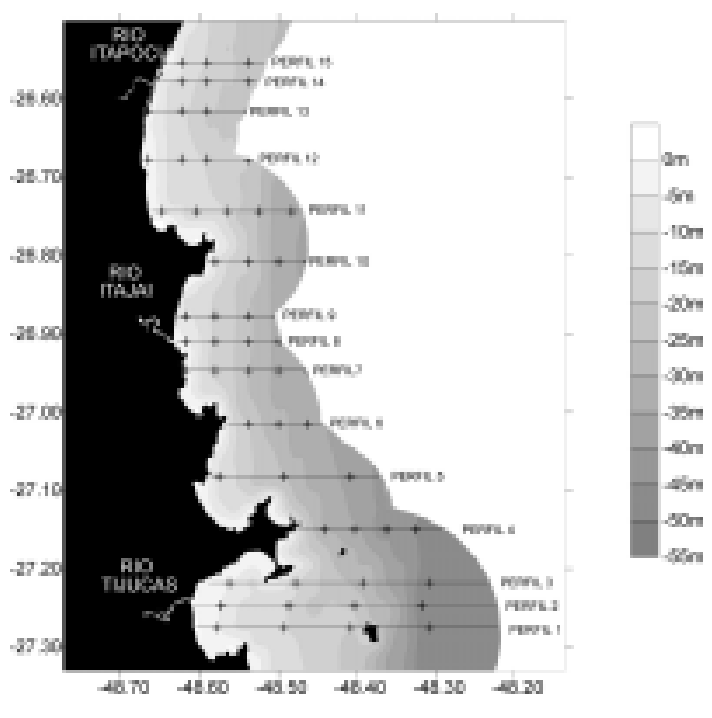

Fig. 2 - Localização dos perfis oceanográficos e batimetria da área de estudo.

posicionadas por GPS, dispostas em 15 perfis paralelos entre si e aproximadamente perpendiculares à direção geral da linha de costa. Utilizou-se um STD SENSORDATA ${ }^{\circledR}$ SD202 preparado para realizar uma leitura a cada 2 segundos. Procurou-se baixar e erguer o equipamento com velocidade aproximadamente constante e menor do que 0.5 $\mathrm{m} / \mathrm{s}$, garantindo-se assim no mínimo uma leitura a cada metro. As informações obtidas foram submetidas a rotinas para avaliação de qualidade e filtragens.

\section{RESULTADOS E DISCUSSÃO}

A distribuição das propriedades foram apresentadas sob a forma de isohalinas e isotermas em planta (Fig. 3, 7, 11, 15) para profundidade de 2 metros e em perfis transversais a costa (Figuras 4, 8, 12 e 16).

A Tabela 1 apresenta os valores máximos, mínimos, médios e desvios padrão de temperatura e salinidade para todos os cruzeiros calculadas para profundidades de 2 , $10,20,30$ e 40 metros. 
Tabela 1 - Estatística dos valores de temperatura e salinidade em profundidades de 2, 10, 20, 30 e 40 metros.

\begin{tabular}{|c|c|c|c|c|c|c|c|c|c|}
\hline & \multirow[b]{2}{*}{$\mathrm{Z}(\mathrm{m})$} & \multicolumn{4}{|c|}{ SALINIDADE (PSU-78) } & \multicolumn{4}{|c|}{ TEMPERATURA $\left({ }^{\circ} \mathrm{C}\right)$} \\
\hline & & MIN & MAX & MEDIA & $\sigma$ & MIN & MAX & MEDIA & $\sigma$ \\
\hline \multirow{5}{*}{$\begin{array}{c}\text { PRIMAVERA } \\
94\end{array}$} & -2 & 28,36 & 34,33 & 33,13 & 1,02 & 21,96 & 25,49 & 23,80 & 0,90 \\
\hline & -10 & 33,59 & 35,23 & 34,36 & 0,44 & 18,24 & 24,04 & 22,25 & 1,22 \\
\hline & -20 & 34,06 & 36,02 & 35,35 & 0,67 & 17,12 & 22,59 & 19,47 & 1,43 \\
\hline & -30 & 34,90 & 36,08 & 35,66 & 0,40 & 16,22 & 18,76 & 17,63 & 0,82 \\
\hline & -40 & 35,44 & 36,00 & 35,57 & 0,18 & 15,88 & 16,56 & 16,22 & 0,21 \\
\hline \multirow{5}{*}{ VERÃO 95} & -2 & 24,74 & 35,55 & 31,84 & 2,65 & 23,39 & 26,82 & 25,09 & 0,85 \\
\hline & 10 & 32,96 & 35,52 & 34,42 & 0,64 & 24,04 & 25,10 & 24,59 & 0,29 \\
\hline & -20 & 34,58 & 35,51 & 35,18 & 0,25 & 24,29 & 24,85 & 24,51 & 0,15 \\
\hline & -30 & 35,19 & 35,62 & 35,38 & 0,11 & 24,32 & 25,02 & 24,58 & 0,19 \\
\hline & -40 & 33,94 & 25,94 & 35,32 & 0,94 & 18,83 & 21,99 & 20,29 & 1,43 \\
\hline \multirow{5}{*}{ OUTONO 95} & -2 & 33,23 & 35,28 & 34,24 & 0,58 & 21,12 & 22,79 & 21,99 & 0,48 \\
\hline & -10 & 33,26 & 35,29 & 34,39 & 0,58 & 21,13 & 22,74 & 21,97 & 0,46 \\
\hline & -20 & 33,31 & 35,44 & 34,42 & 0,66 & 21,14 & 22,93 & 22,00 & 0,54 \\
\hline & -30 & 33,34 & 35,02 & 34,37 & 0,67 & 21,17 & 22,49 & 21,98 & 0,54 \\
\hline & -40 & 33,56 & 34,68 & 34,02 & 0,46 & 21,30 & 22,48 & 21,77 & 0,51 \\
\hline \multirow{5}{*}{ INVERNO 95} & -2 & 26,20 & 32,27 & 29,84 & 1,45 & 17,39 & 19,04 & 18,07 & 0,31 \\
\hline & -10 & 30,65 & 32,48 & 31,55 & 0,45 & 17,62 & 18,13 & 17,81 & 0,13 \\
\hline & -20 & 31,66 & 34,03 & 32,34 & 0,48 & 17,63 & 19,17 & 17,96 & 0,29 \\
\hline & -30 & 31,80 & 34,90 & 33,39 & 0,99 & 17,66 & 19,98 & 18,61 & 0,79 \\
\hline & -40 & 33,84 & 34,92 & 34,36 & 0,44 & 18,74 & 19,63 & 19,11 & 0,41 \\
\hline
\end{tabular}

Os diagramas TS, para cada cruzeiro, são apresentados nas Figuras 5, 9, 13 e 17. Procurou-se enriquecer a informação dos TS atribuindo-se tamanhos diferentes aos círculos que representam um par TS fazendo com que estes fossem diretamente proporcionais as suas latitude. Assim sendo, os círculos maiores referem-se aos pares TS obtidos em latitudes maiores, ou seja, mais ao sul. A fim de obter-se uma idéia aproximada da profundidade de coleta dos pares TS, superpôs-se um gráfico em curva de nível da profundidade, no qual esta é o termo dependente e a temperatura e a salinidade são os termos independentes.

As figuras 6, 10, 14 e 18 apresentam séries temporais de vento obtidos na plataforma de petróleo PXIV (26 46' S, 048 47' $W)$ para os meses em que foram realizados os cruzeiros oceanográficos e os imediatamente anteriores. Cabe ressaltar que a convenção adotada para a representação dos vetores de vento seguiu a convenção vetorial e não a convenção meteorológica. Assim sendo, as extremidades dos vetores indicam a direção de para onde o vento está se dirigindo. Convencionar-se-á como ventos do quadrante sul aqueles cujos vetores estiverem representados no lado positivo do gráfico, independente destes provirem de SE ou SW. O oposto vale para os ventos do quadrante norte.

As distribuições horizontais de salinidade e temperatura a 2 metros da superfície na primavera de 94 (Fig. 3-a e 3-b) evidenciaram o trajeto de uma língua de água menos salina afastando-se do Rio Itajaí em direção o sul, junto à costa. Ao mesmo tempo, foi possível observar um gradiente decrescente de temperatura partindo do norte para o sul da área de estudo com a formação um núcleo de água fria $\left(<22.0^{\circ} \mathrm{C}\right)$ nas proximidades da Ilha do Arvoredo indicando o afloramento de uma ressurgência costeira. A 
ressurgência também apareceu bem evidenciada nos perfis de salinidade e temperatura para esta mesma região (fig. 4-a e 4-b). A intensidade da ressurgência diminuiu em di-
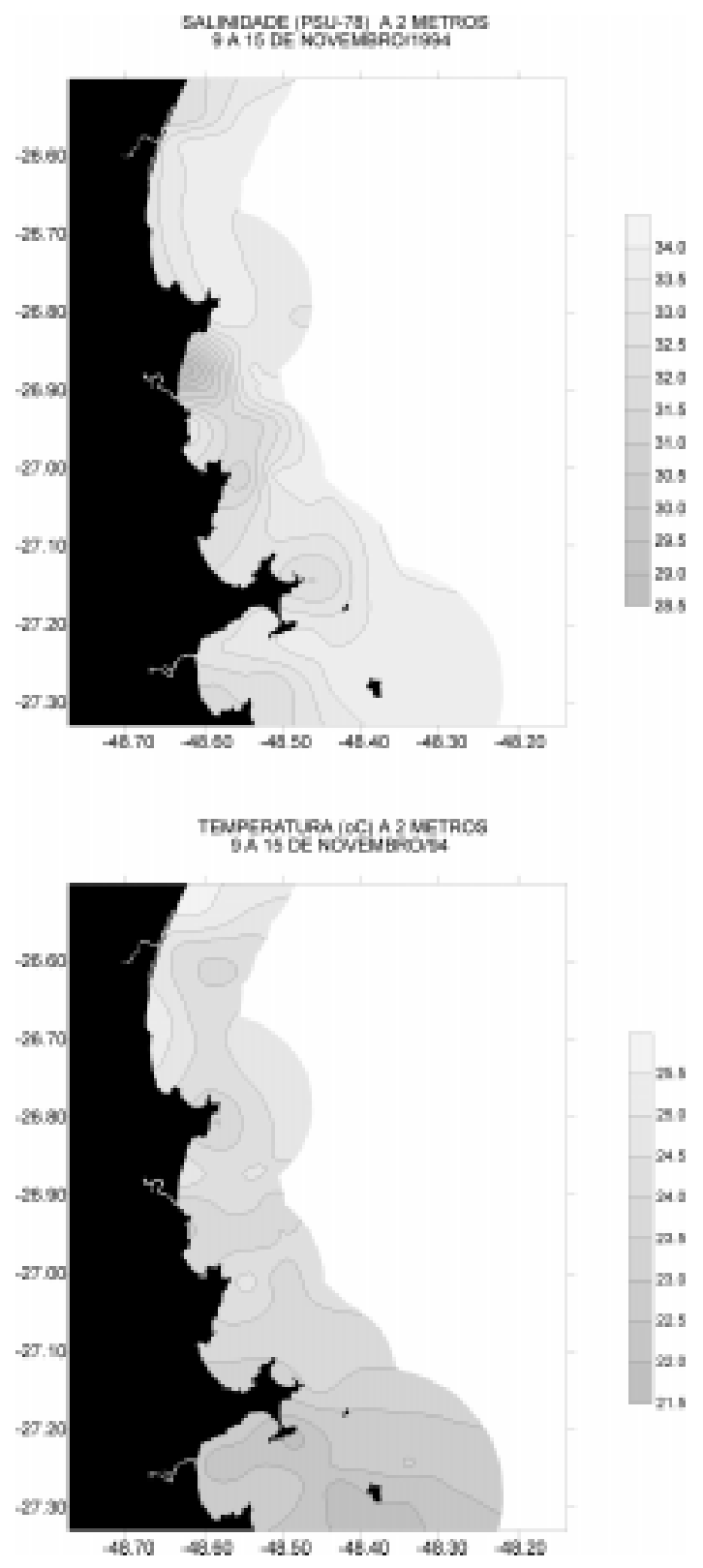

Fig. 3 - Isohalinas (a) e Isotermas (b) em planta para a profundidade de 2 metros no cruzeiro da primavera de 94. reção ao norte uma vez que as isotermas se tornaram paralelas à superfície a partir do perfil 10. Isto pode estar associado a um relaxamento do vento NE ao longo da realização do cruzeiro ou pode também indicar que a região sul do LCNC é mais suscetível a eventos de ressurgência. Infelizmente, as escalas temporais e espaciais deste estudo não foram adequadas para investigar o fenômeno. No diagrama TS (fig. 5) pôde-se observar duas massas d'água predominantes: a $\mathrm{AC}$, que apresentou o valores de salinidade centrados entre 33,5 e 34,5 e temperatura entre 21,5 e $24,8^{\circ} \mathrm{C}$; e, nos extratos mais profundos, a parte superior da ACAS, predominando salinidade entre 35,4 e 35,9 e temperatura entre 15,7 e $18,0^{\circ} \mathrm{C}$. A mistura entre elas também esteve bem representada no diagrama pela reta que une as mesmas. À superfície houve dispersão dos pares TS em função da diminuição da salinidade causada pelo aporte continental.

Na figura 6 pôde-se observar que próximo ao período de realização da campanha de primavera (5 a 12 de novembro) ocorreu a repetição de uma seqüência de eventos semelhantes nos quais ventos fortes (> $15 \mathrm{~m} / \mathrm{s}$ ) soprando do quadrante norte com persistência superior a 5 dias foram intercalados por ventos vindos do quadrante sul que, embora intensos, foram pouco persistentes (1 a 2 dias). O evento de ressurgência costeira observado na campanha de primavera sobre o LCNC pode então ser perfeitamente explicado pelo modelo proposto em Castro, 1990.

No verão de 95, a distribuição horizontal de salinidade a 2 metros de profundidade (Fig. 7-a) mostrou claramente a influência do aporte dos três rios principais da região. O rio Itajaí influenciou toda a região costeira ao norte de sua foz, sugerindo que a corrente predominante no período de amostragem seguiu a direção sul-norte. Ao sul, na área da Ilha do Arvoredo, a influência do rio Tijucas e das águas salgadas da plataforma formaram um gradiente horizontal muito acentuado. A distribuição de temperatura superficial apre- 


\section{A 15 DE NOVEMBRO/1984}
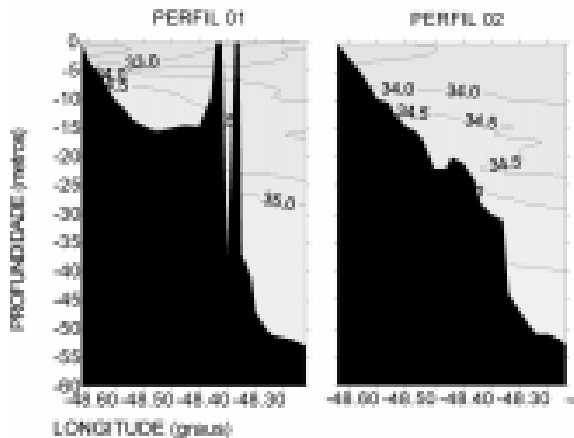

$-4160-465-4140-48.25$
DenriL os

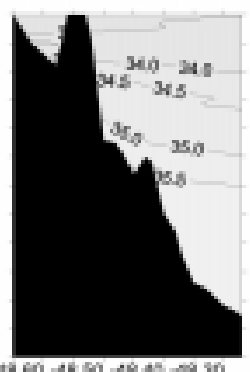

\section{SALINIDADE (PSU-78)}

PERTIL OA pernilos perul os
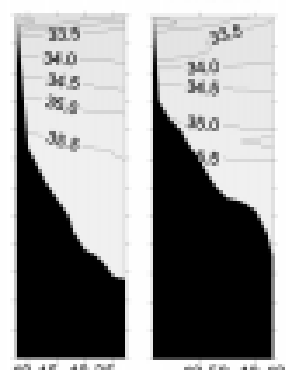

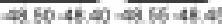

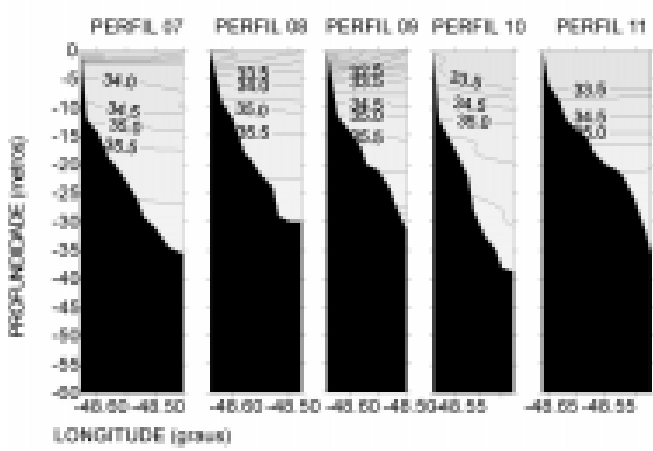

9 A 15 DE NOVEMBRO/1994

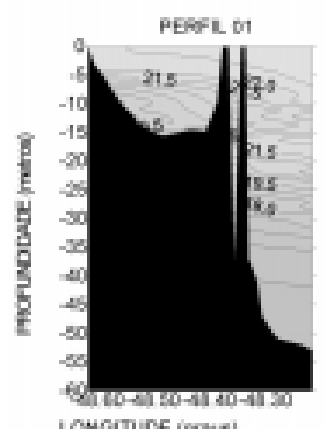
LONGTUDE igras!

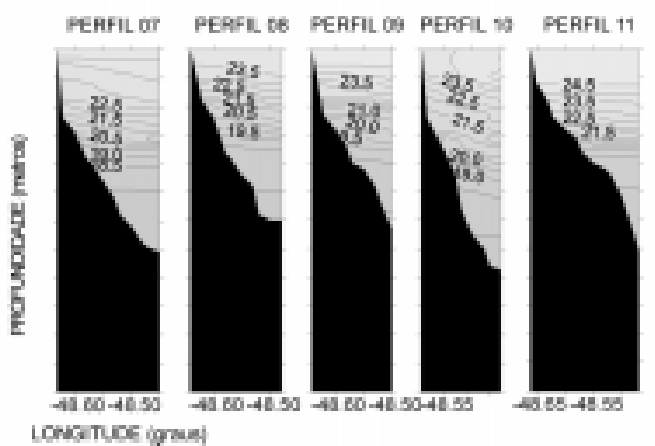

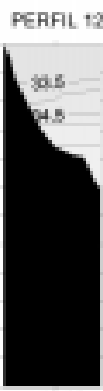

40.20

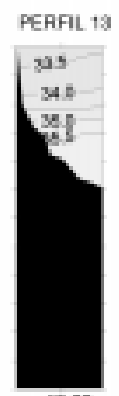

40.00

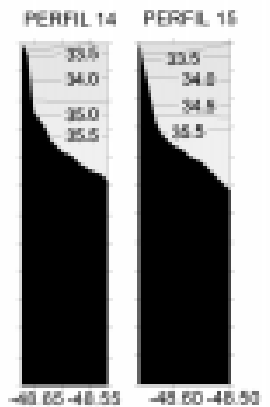

TEMPERATURA (OC)

PEAPL OS PERFL DS PEREL, DE
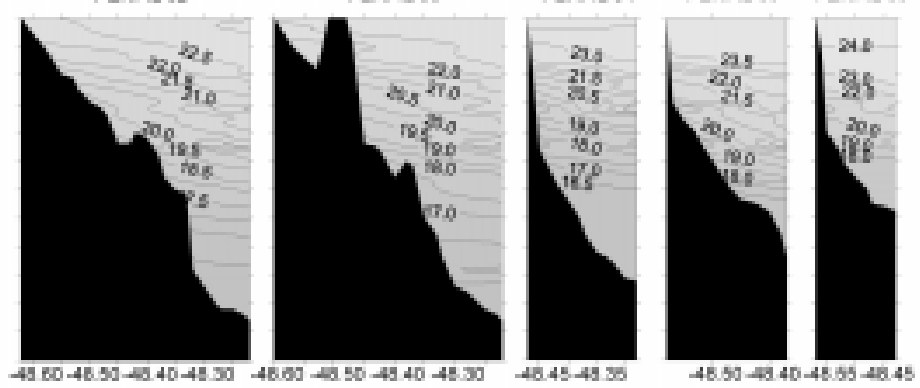

PEFAL 12 PERFK 18 PEFFL 14 PEFFL 15

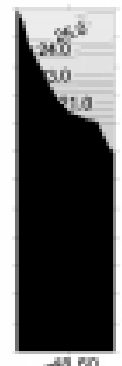

$-4360$
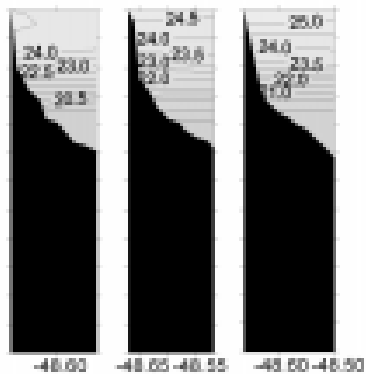

Fig. 4 - Isohalinas (a) e Isotermas (b) dos perfis transversais da primavera de 94. 


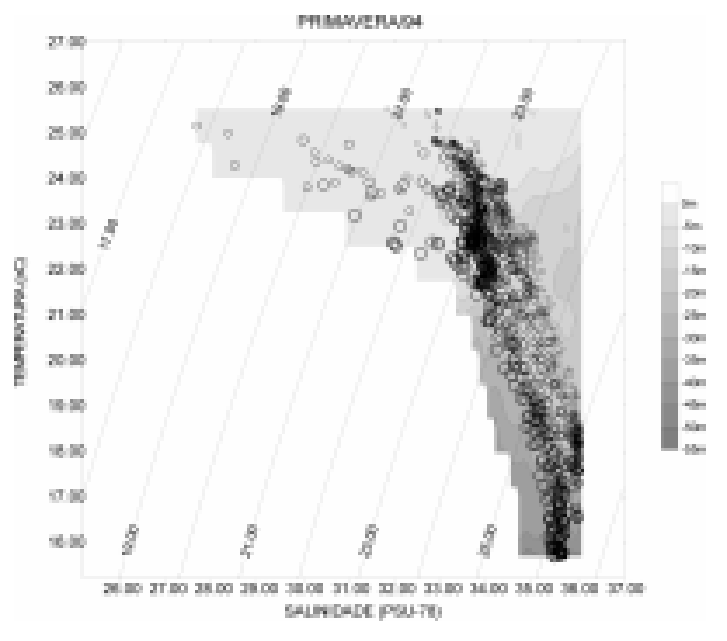

Fig. 5 - Diagrama TS do cruzeiro de primavera de 94.

sentou um gradiente ascendente do sul para o norte. Como a coluna d'água estava bastante estratificada (figs. 8-a e 8-b) durante o período de amostragem e não havia indícios de ressurgência costeira no local, é possível que esta gradação horizontal de temperatura deveu-se a um evento anterior de ressurgência dentro do LCNC ou a uma advecção de águas mais frias provindas do sul. Esta hipótese é reforçada pelo indício de que a corrente costeira fluía de sul para norte. Nos perfis verticais salinidade (figs. 8a) a disposição vertical das isohalinas sugere ter havido uma subsidência de águas junto à costa. Nos perfis de temperatura (figs 8-b) o mesmo padrão foi observado. A coluna d'água esteve praticamente homogênea até 35 metros, com valores variando entre 24,5 e $25,0{ }^{\circ} \mathrm{C}$. Abaixo desta observou-se uma termoclina acentuada localizada entre 35 a 40 metros de profundidade. Abaixo de 40 metros encontrou-se o topo da ACAS com temperaturas em torno de $18-19^{\circ} \mathrm{C}$. O diagrama TS (Fig. 9) mostrou claramente a concentração dos pares TS entre 33,0 e 35,8 de salinidade e 24,0 e $25,0^{\circ} \mathrm{C}$ de temperatura. Abaixo dos 40 metros os pares concentraramse numa salinidade de 36,0 e temperatura variando entre 18,2 e $19,0^{\circ} \mathrm{C}$. Foi possível perceber também a pouca mistura entre as duas águas. A dispersão dos pares TS em função da salinidade em águas superficiais evidenciou a influência do aporte continental. Observou-se também a gradação horizontal de temperatura de sul para norte através do tamanhos das circunferências.
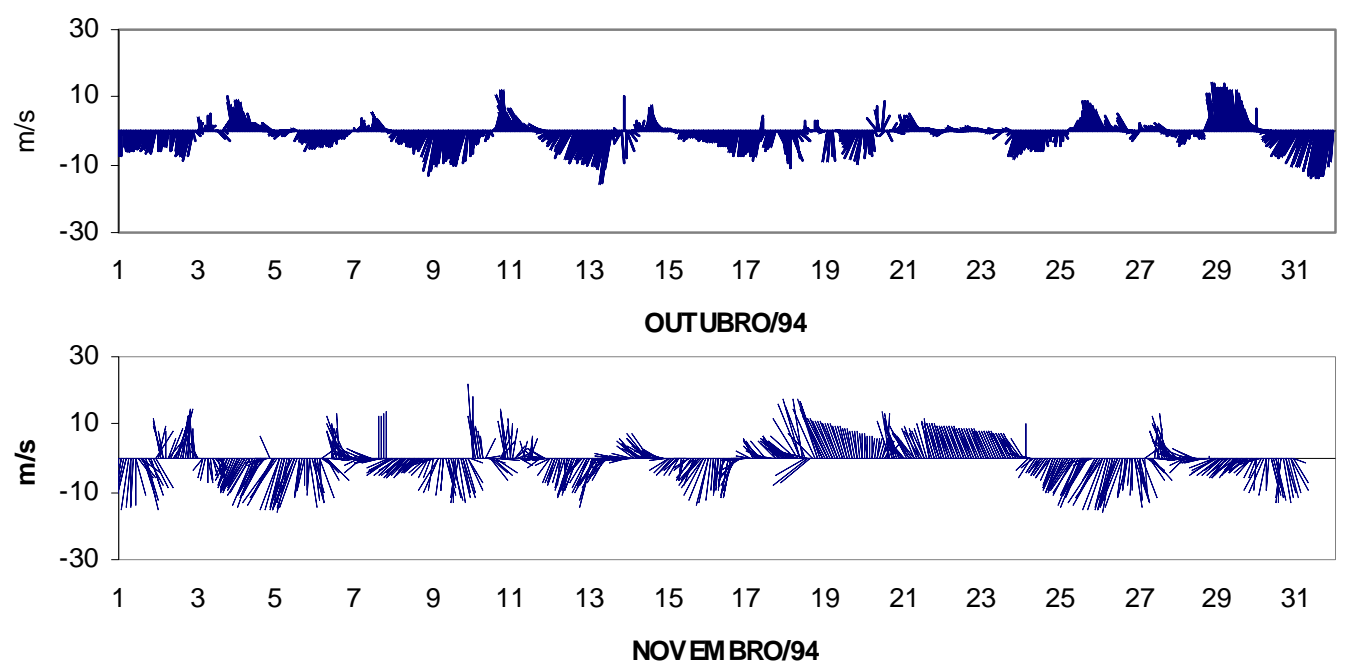

Fig. 6 - Série temporal de vento medido em P-XIV no mês do cruzeiro de primavera de 94 e no imediatamente anterior. 
Na campanha de verão os ventos sopraram fracos do quadrante sul (Fig. 10). A semana anterior à realização da campanha foi caracterizada por ventos fortes e persis-
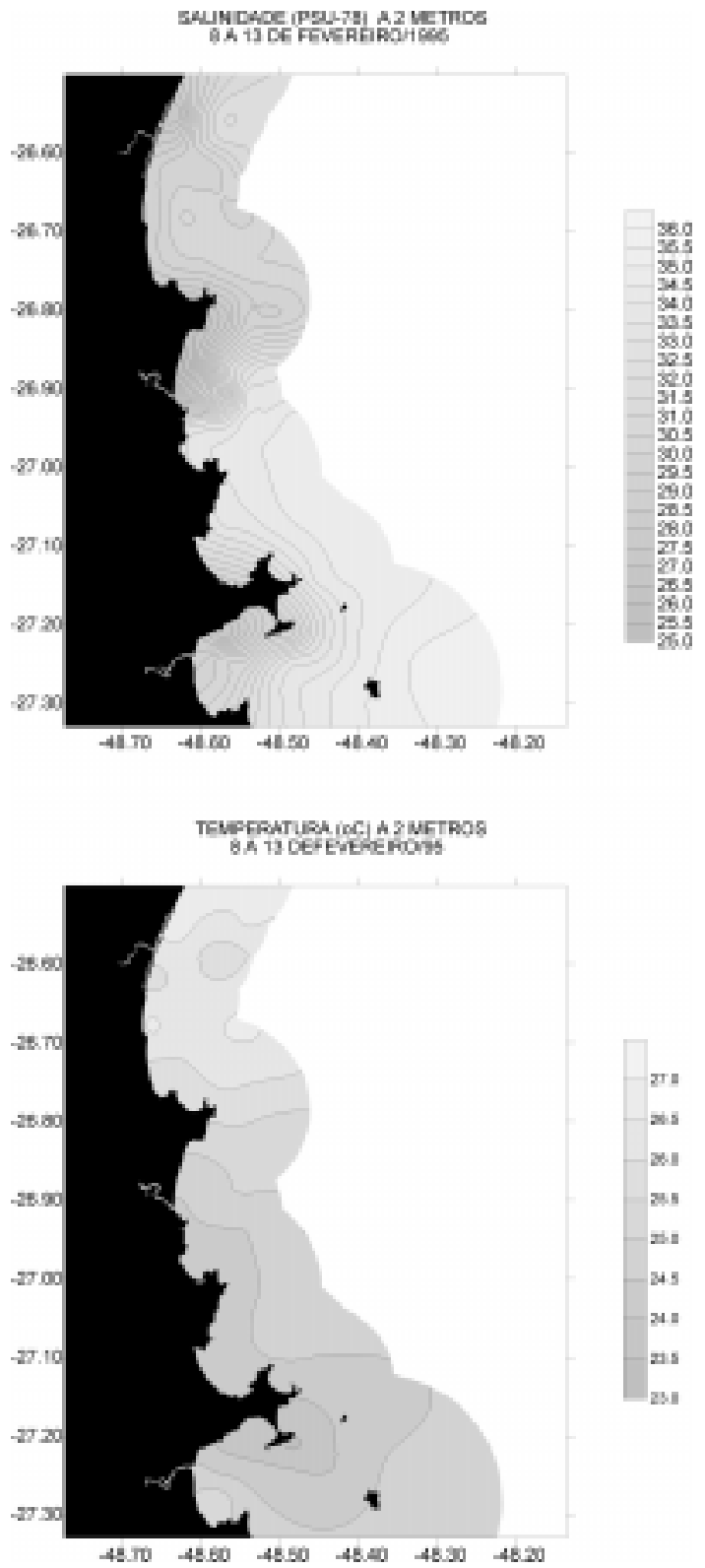

Fig. 7 - Isohalinas (a) e Isotermas (b) em planta para a profundidade de 2 metros no cruzeiro do verão de 95 . tentes vindos também de sul. Este fato pode explicar a deflexão das águas sob influência dos rios para o norte, assim como o fato das isohalinas e isotermas da massa d'água superior indicarem ter havido subsidência de água junto à costa forçando o afundamento da termoclina para uma profundidade de 35 metros.

O outono (Figs. 11, 12, e 13) foi caracterizado pela presença de águas muito homogêneas em toda a área de estudo. Não foi observada a influência dos rios da região sobre a distribuição de salinidade superficial verificada na primavera e no verão. Contrariamente ao padrão anterior observou-se um ligeiro gradiente ascendente de salinidade e temperatura de leste para oeste sugerindo uma convergência de águas mais frias e menos salgadas, anteriormente localizadas mais ao largo, para a costa. Os perfis perpendiculares de salinidade e temperatura apresentaram um padrão de isohalinas e isotermas aproximadamente verticais evidenciando a subsidência das águas costeiras. O diagrama TS mostrou o padrão homogêneo da coluna com valores de salinidade variando entre 33,2 e 35,6 e temperatura entre 21,0 e $23,0^{\circ} \mathrm{C}$.

Nos períodos próximos à realização da campanha de outono, observou-se uma seqüência de ventos fracos vindos de norte intercalados por ventos intensos vindos de sul (Fig. 14), porém um pouco menos persistentes. Em 15 e 25 dias antes, no entanto, foram registrados os ventos mais intensos de 95 , ambos vindos do quadrante sul e com persistência de 5 dias. O efeito destes eventos sobre a coluna d'água podem ter perdurado, uma vez que os ventos de norte subsequentes foram fracos.

O inverno de 95 foi marcado pela presença de uma massa d'água fria e de baixa salinidade em toda a área de estudo. O gráfico de salinidade a 2 metros (fig. 15-a) indicou que as plumas dos rios da região dirigiram-se para norte. Pôde-se observar no gráfico de distribuição de temperatura (fig. 15-b) 


\section{A 13 DE FEVEREIRO/1995}
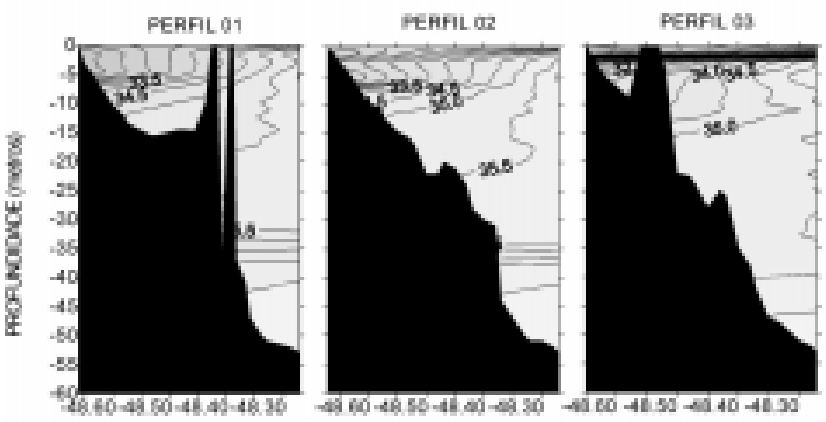
Lonatude gomin
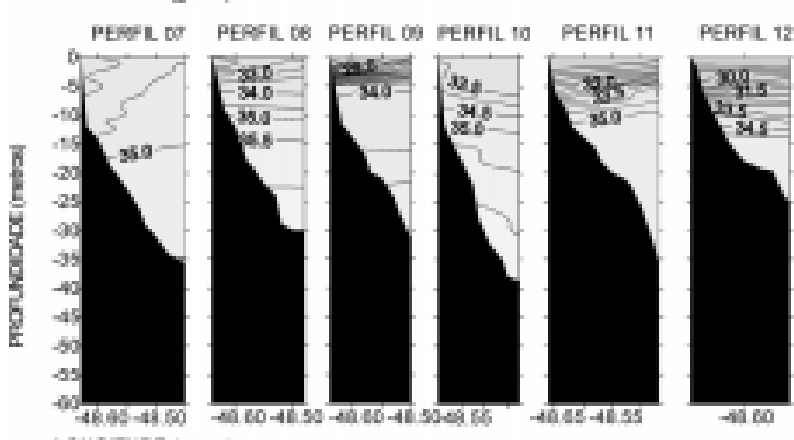
LONOTUCE ignus!

\section{A 13 DE FEVEREIRO/1995}
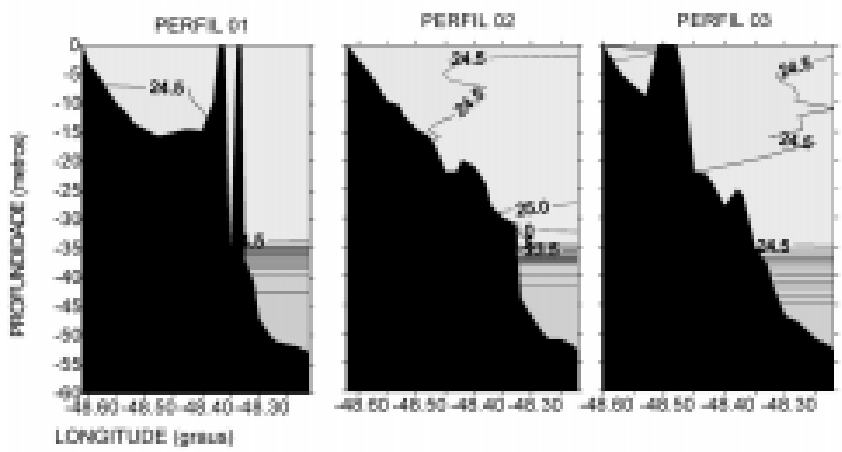

PEOTL DS

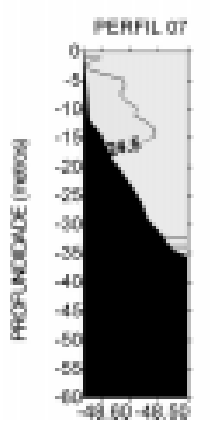

REAPIL os

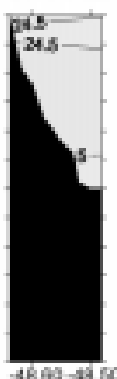

PEAFIL OD PEAFE 10
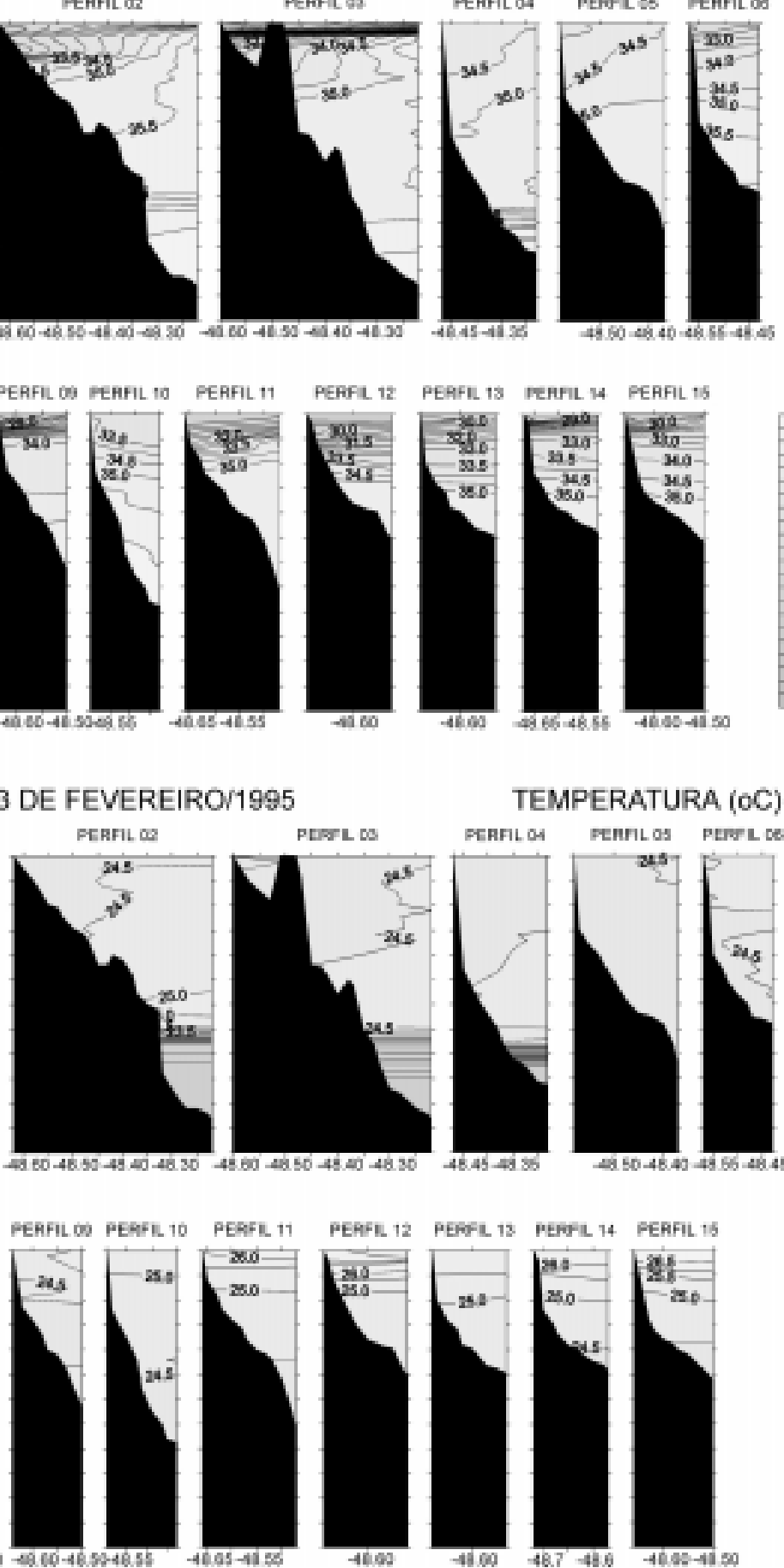

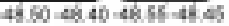
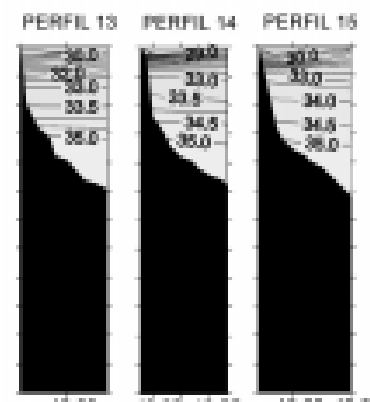

$-4600$
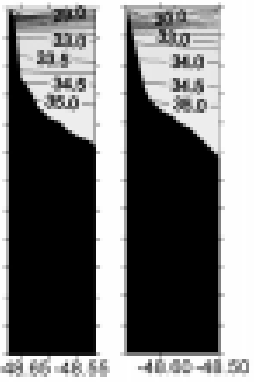

TEMPERATURA (OC)

PERFLOS PEMTLOS PEVL De

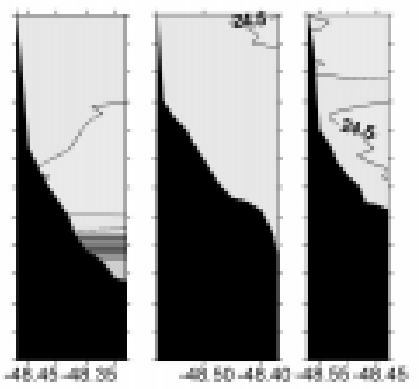

Fig. 8 - Isohalinas (a) e Isotermas (b) dos perfis transversais do verão de 95. 


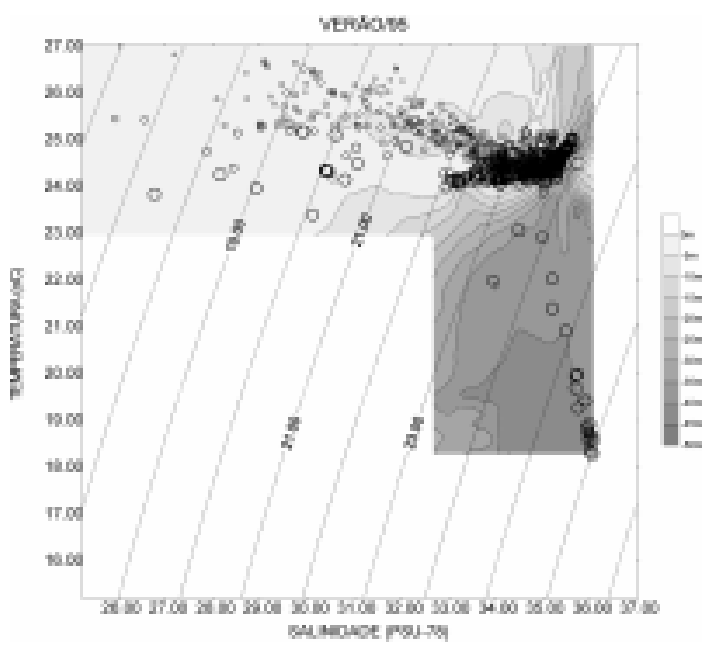

Fig. 9 - Diagrama TS do cruzeiro de verão de 95.

um gradiente ascendente do sul para o norte provavelmente associado ao aquecimento superficial gerado pelo bom tempo que consolidou-se no decorrer do cruzeiro. Os perfis verticais de temperatura (figs. 16-b) mostraram uma coluna d'água fria e homogênea apresentando uma inversão térmica considerável abaixo dos 30 metros de profundidade. A estabilidade da coluna d'água foi garantida pela salinidade (Fig. 16-a) que apresentou uma estratificação vertical acentuada, não só nas áreas localizadas em frente aos rios principais mas como em toda a LCNC. A contribuição continental, novamente só fez-se sentir nas camadas superficiais. O diagrama TS (Fig. 17) apresentou concentração de pares entre 29,7 e 33,0 de salinidade e 17,4 e 18,2 ${ }^{\circ} \mathrm{C}$ de temperatura. Observou-se a dispersão de pares no TS em função da diminuição da salinidade causada pela influência dos rios da região. Em profundidades maiores, o padrão retilíneo do TS sugeriu que houve mistura desta água superficial com uma água localizada em maior profundidade, e portanto fora da nossa área de amostragem, com temperatura e salinidade superiores.

A campanha de inverno foi iniciada sob a ação de um vento de sul intenso com persistência de 2,5 dias seguido de um giro gradual para NE permanecendo assim até o final do período (Fig. 18). Como os valores de salinidade e temperatura encontrados sobre o LCNC neste cruzeiro foram muito baixos e as isohalinas não indicaram grande influência continental, supõe-se que esta massa d'água seja um prolongamento da ACISA sobre a região sul da PCSE.
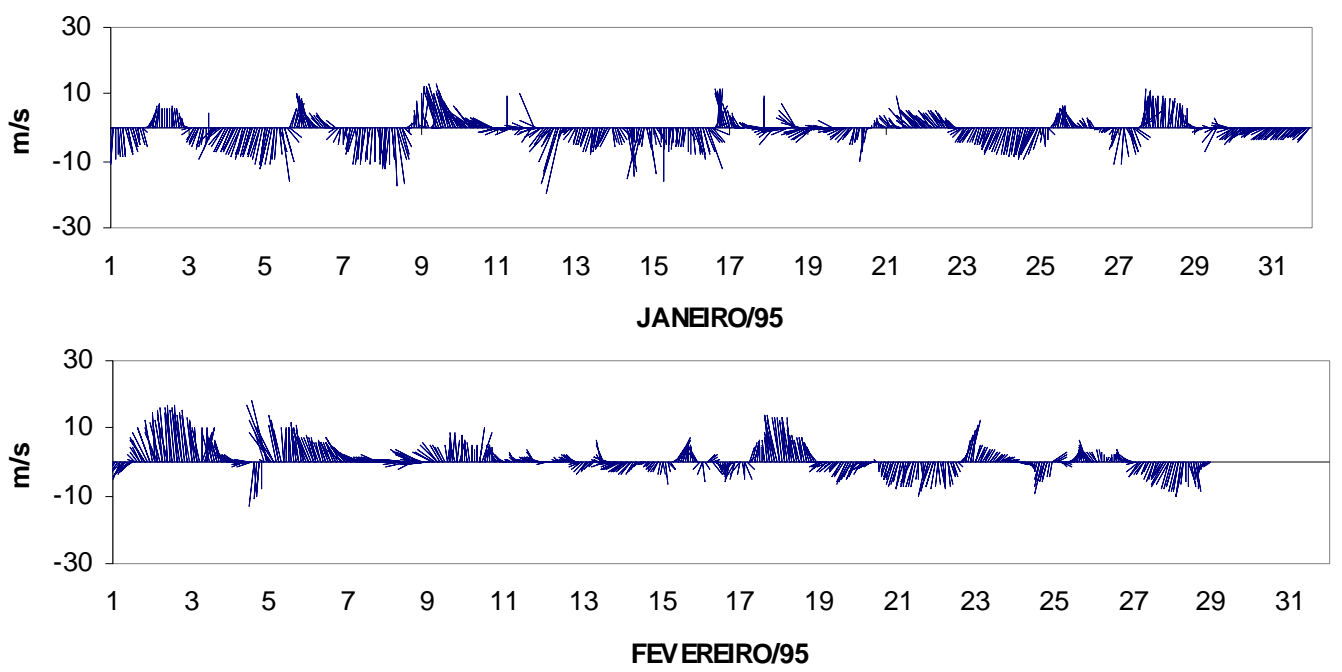

Fig. 10 - Série temporal de vento medido em P-XIV no mês do cruzeiro de verão de 95 e no imediatamente anterior. 
As séries temporais de vento mostraram que a persistência e a intensidade dos ventos, tanto de norte quanto de sul, variaram do inverno para o verão sobre a PCSE.
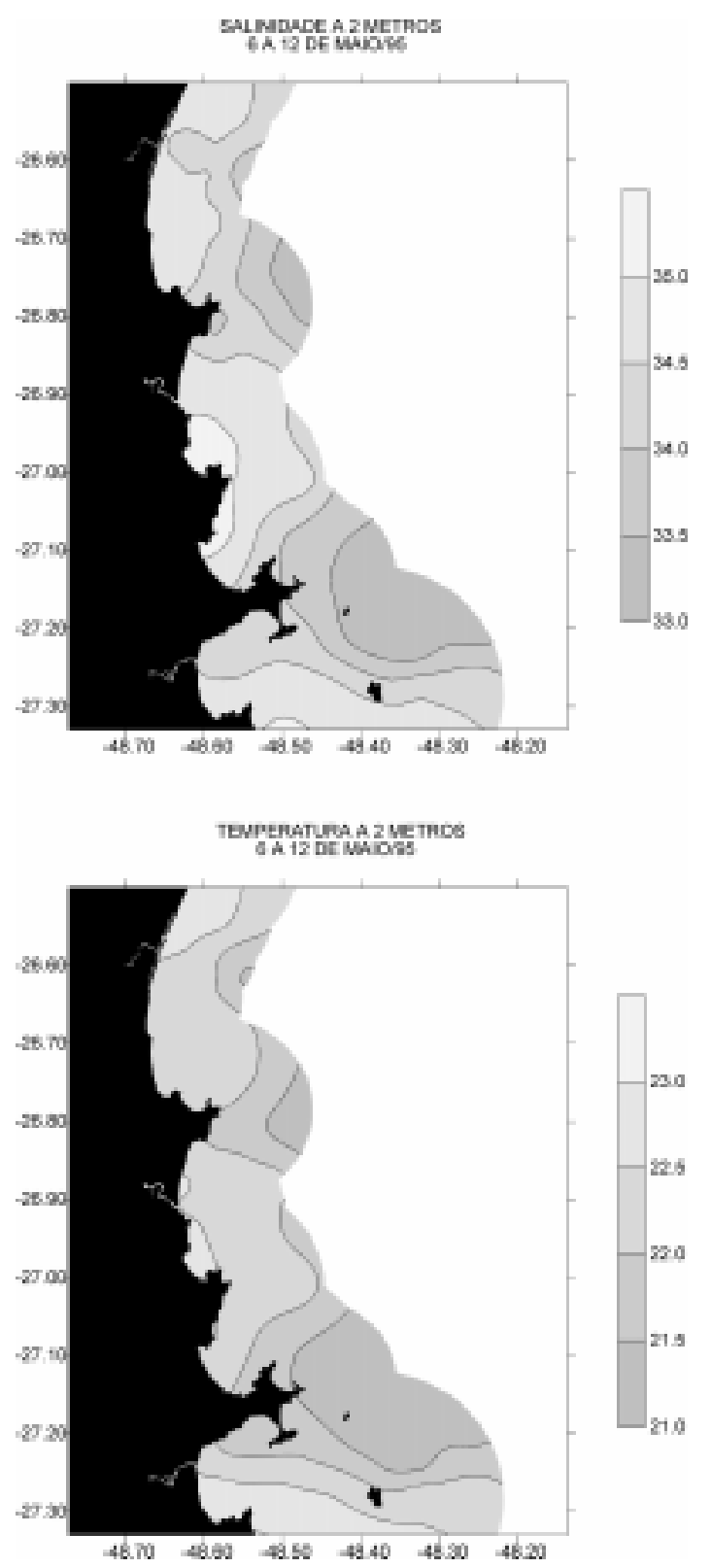

Fig. 11 - Isohalinas (a) e Isotermas (b) em planta para a profundidade de 2 metros no cruzeiro do outono de 95.
Isto é resultado da migração sazonal dos centros de alta pressão que regulam a passagem de sistemas frontais no Atlântico Sul. No verão, quando o Anticiclone do Atlântico Sul (AAS) está posicionado mais ao sul, os ventos do quadrante norte são mais intensos e persistentes do que no inverno. No inverno, o Anticiclone Móvel Polar (AMP), mais fortalecido, empurra o AAS para o norte e os ventos de norte são menos intensos e persistentes do que no verão. O inverso deste padrão sazonal também é observado para os ventos vindos do quadrante sul.

As campanhas de primavera e verão, além de mostrar padrões de estratificação típicos do período, mostraram também o efeito de ventos com direções opostas sobre este tipo de coluna d'água. Os ventos de norte produziram ressurgência e os de sul subsidência. E como estes eventos repetemse dezenas de vezes durante o período, é possível imaginar a grande importância ecológica deste fenômeno, principalmente para a produção primária.

\section{CONCLUSÕES E RECOMENDAÇÕES}

Os padrões de massas d'água encontrados no LCNC nos quatro cruzeiros oceanográficos concordaram plenamente com 0 que fora descrito anteriormente na bibliografia citada. Pelo fato da área estar localizada ao sul da PCSE também foram observados no inverno a presença de massas d'água típicas da PCS.

A distribuição de massas d'água no LCNC pode ser resumida nos seguintes padrões:

Situação de primavera-verão: Coluna d'água em duas camadas com a presença de uma termoclina bastante acentuada. Os ventos vindos do quadrante norte provocam a ressurgência costeira da ACAS. Já os ventos de sul provocam a subsidência de águas junto à costa com afundamento da termoclina. 


\section{A 12 DE MAIO/1995}

SALINIDADE (PSU-78)
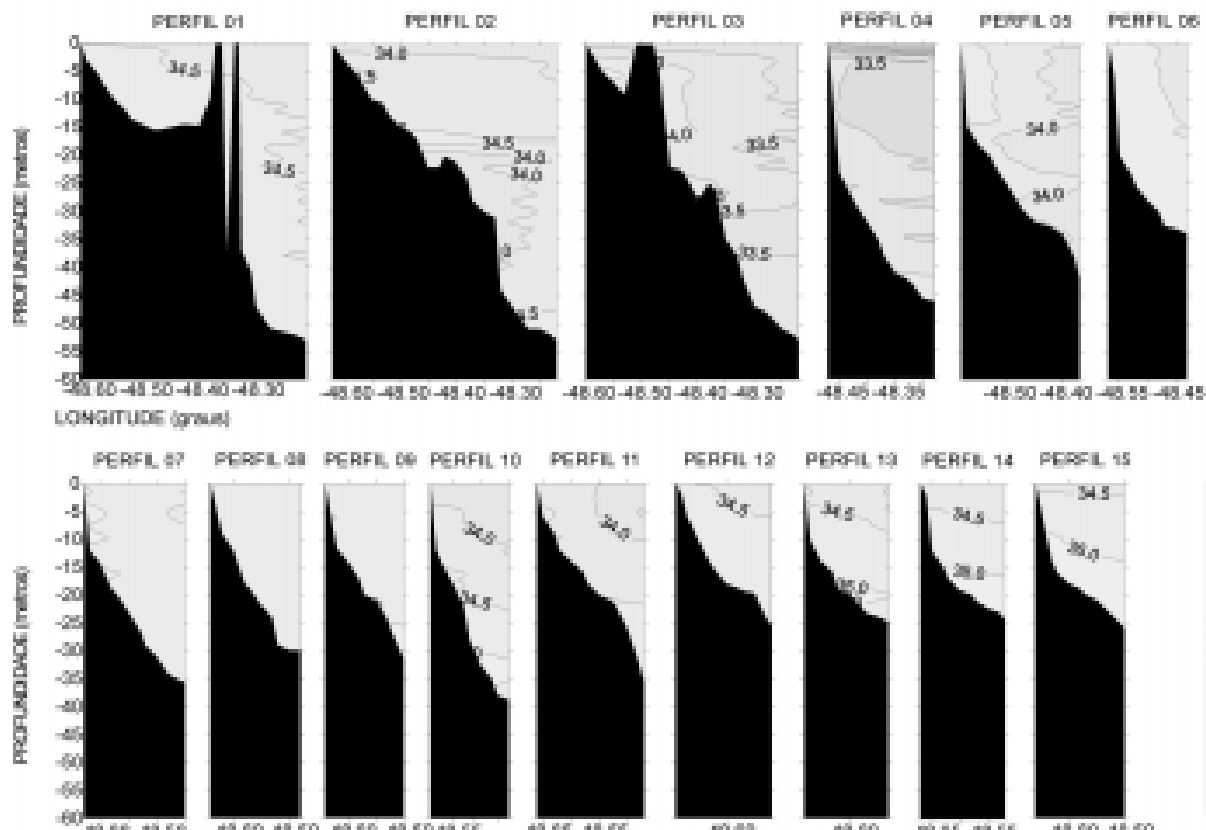

PSAFIL 12

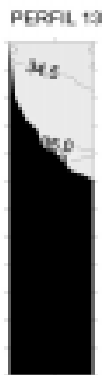

LONGCTUDE igous:

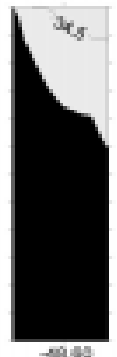

sing

$-4360$

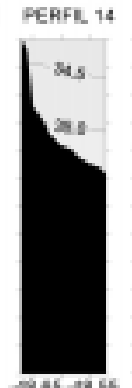

PFPFA. is

6 A 12 DE MAIO/1995

TEMPERATURA (OC)
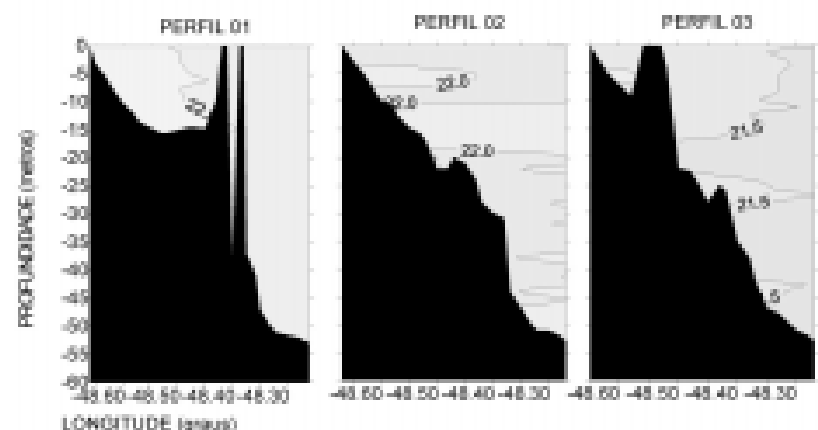

PENTIL o

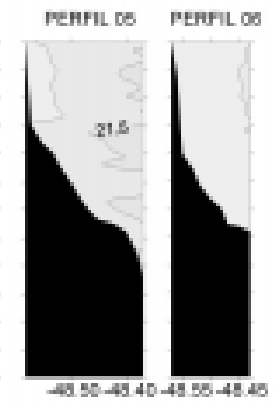
Lencitud (avani)
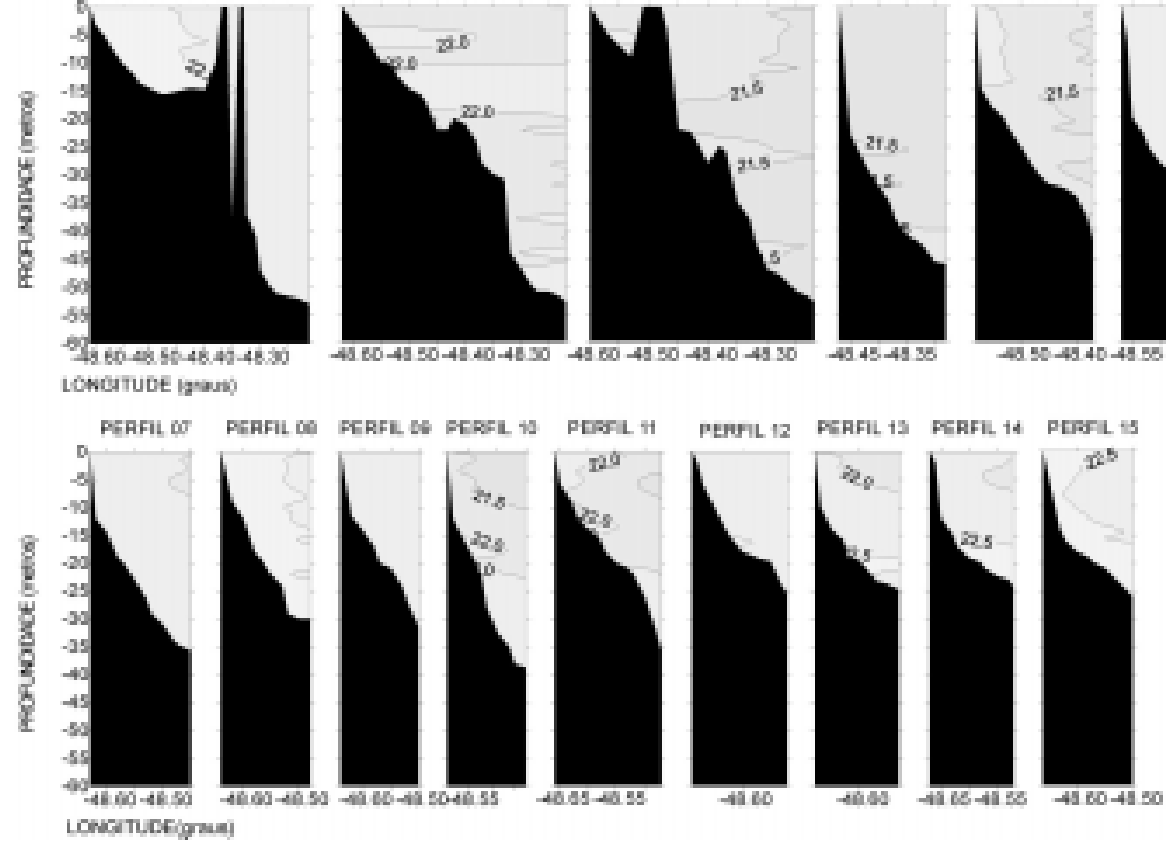

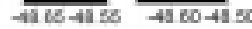

Fig. 12 - Isohalinas (a) e Isotermas (b) dos perfis transversais do outono de 95. 


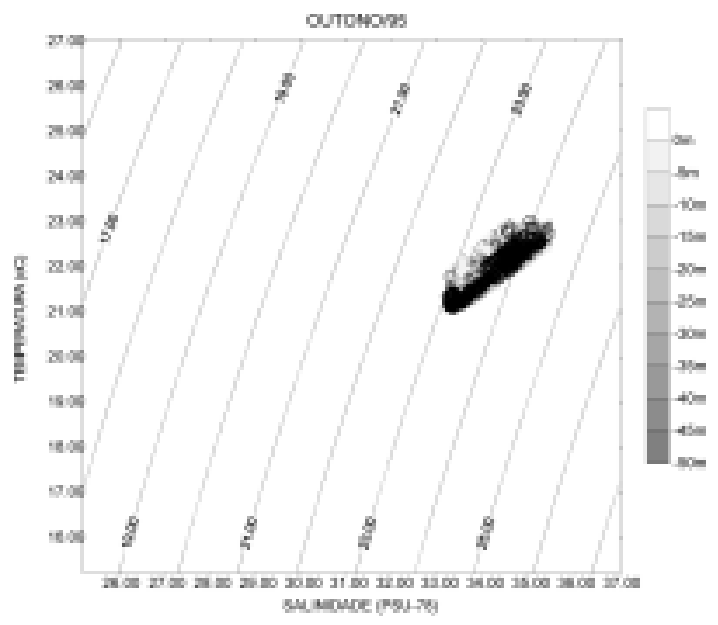

Fig. 13 - Diagrama TS do cruzeiro de outono de 95.

Situação de outono-inverno: Coluna d'água homogênea causada tanto pela subsidência costeira devido ao aumento da magnitude e persistência dos ventos de sul, como pela advecção de águas de origem subantártica influenciada pelo aporte continental do Rio da Prata e Lagoa dos Patos.

A influência dos rios da região ocorre nas camadas superficiais podendo alcançar mai- ores profundidades caso esteja havendo um evento de subsidência de águas junto à costa. Os rios Itapocu e Tijucas tem uma influência limitada às proximidades do estuário. O rio Itajaí influencia uma área maior, tanto para o norte quanto para o sul, seguindo a direção do vento predominante.

Recomenda-se que os futuros estudos de ecologia básica ou monitoramento de organismos sejam conduzidos em escalas temporal e espacial adequadas com os padrões de circulação e mistura aqui apresentados. Sugere-se ainda o monitoramento contínuo de nível d'água, vento, pressão atmosférica, pluviosidade, temperatura e salinidade da água através de estações fixas distribuídas ao longo da costa para que os processos ecológicos sejam entendidos plenamente.

\section{AGRADECIMENTOS}

Os autores agradecem ao IBAMA/ CEPSUL pela disponibilização do N. Pq. Diadorim para a realização dos cruzeiros oceanográficos. Especial agradecimento à tripulação do navio pelos serviços prestados. À
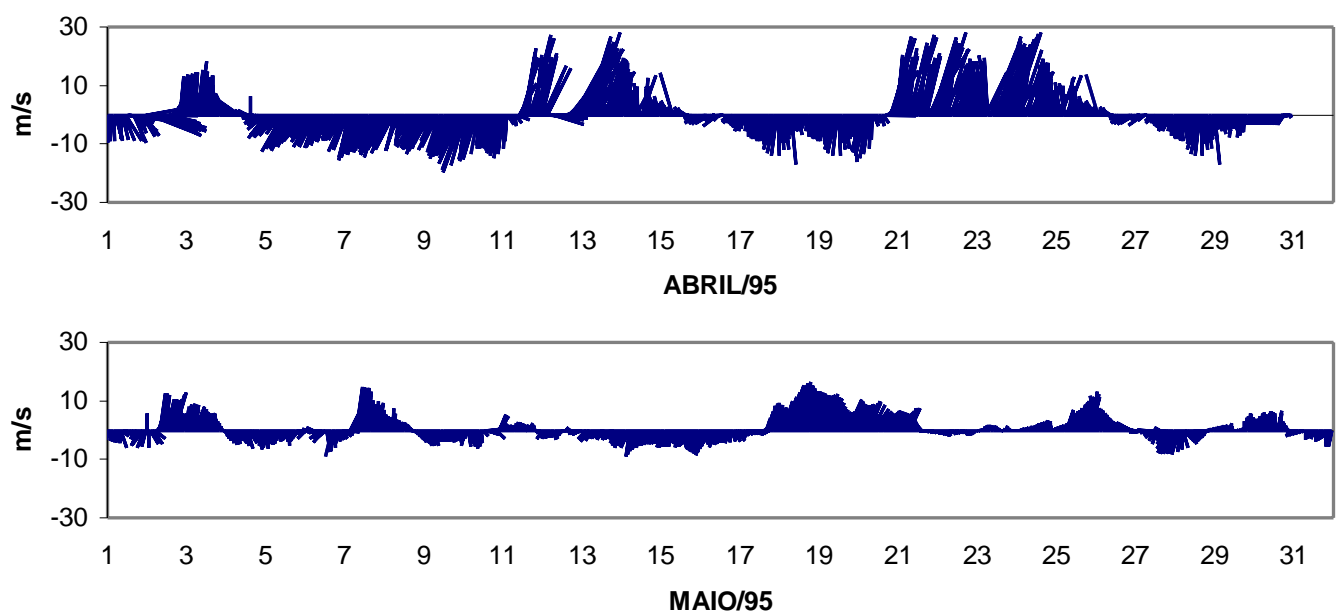

Fig. 14 - Série temporal de vento medido em P-XIV no mês do cruzeiro de outono de 95 e no imediatamente anterior. 
Fundação Banco do Brasil pela disponibilização dos recursos utilizados neste trabalho.
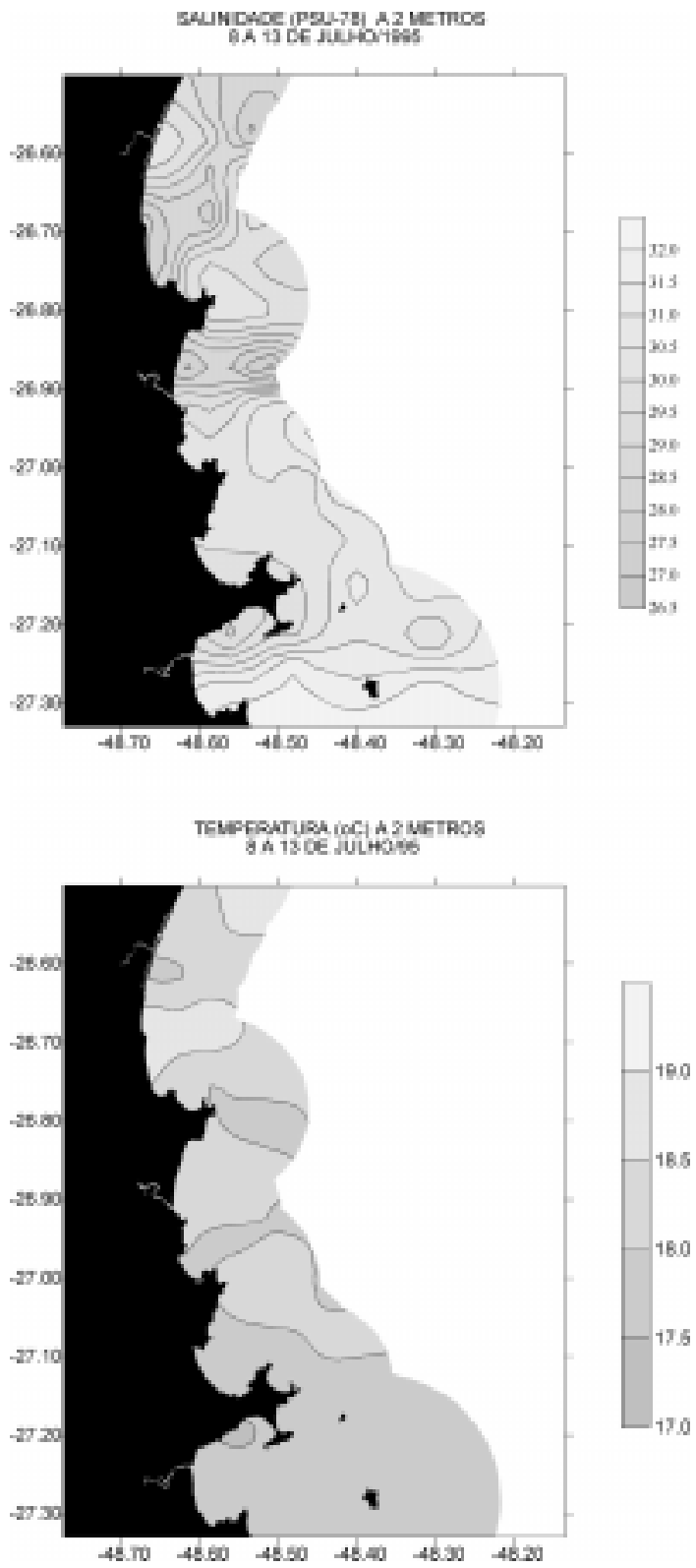

Fig. 15 - Isohalinas (a) e Isotermas (b) em planta para a profundidade de 2 metros no cruzeiro do inverno de 95.

\section{REFERÊNCIAS BIBLIOGRÁFICAS}

Castro Filho, B.M.C. 1987. Condições oceanográficas na plataforma continental ao largo de Ubatuba: Variações sazonais e em média escala. Bol. Inst. Oceanogr., São Paulo, 35(2):135-151.

Castro Filho, B.M.C. 1990. Estado atual do conhecimento dos processos físicos das àguas da Plataforma Continental Sudeste do Brasil. Anais do II Simpósio de Ecossistemas da Costa Sul e Sudeste Brasileira. ACIESP. 1:1-19.

Castro Filho, B.M.C. 1998. Physical Oceanography of the Western Atlantic Continental Shelf located between $4^{\circ} \mathrm{N}$ and $34^{\circ} \mathrm{S}$. The Sea. John Wiley \& Sons, Inc.. 11:209-251.

Emilson, I. 1961. The shelf and coastal waters off southern Brazil. Bol. Inst. Oceanogr. São Paulo, 11(2):101-112.

INPH. 1985. Comportamento hidráulico e sedimentológico do estuário do rio ItajaíAçu - SC. Relatório Técnico INPH 74/85 Código: Itajaí-700/03. 34p.

Matsuura, Y. 1986. Contribuição ao estudo da estrutura oceanográfica da região Sudeste entre Cabo Frio (RJ) e Cabo de Santa Marta Grande (SC). Ciência e Cultura 38(8):1439-1450.

Miranda, L.B. \& Castro Filho, B.M. 1979. Aplicação do diagrama T-S estatístico volumétrico à análise das massas de água da Plataforma Continental do Rio Grande do Sul. Bol. Inst. Oceanogr. São Paulo, 28(1):185-200.

Perez, J.A.A.; Schettini, C.A.F.; Buratto, J. R. \& Machado, M. J. 1997. A pesca de lulas (Mollusca: Cephalopoda) na Ilha do Arvoredo (SC): Características e Relações Ecológicas, Verão de 1996. Notas Técnicas da Facimar, 1:9-21.

Reuss-Strenzel, G.M.; Chludinski, A. P. \& Warlich, R. 1997. Monitoramento Visual de Atividades Antrópicas na Reserva Biológica Marinha do Arvoredo, Santa 
8 A 13 DE JULHOV1995

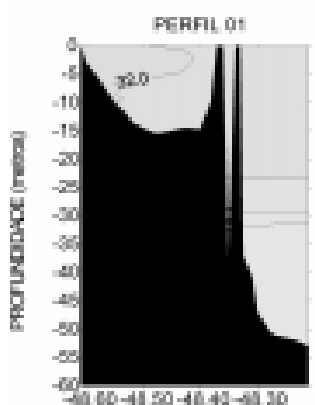
LONaITUDE igrosi

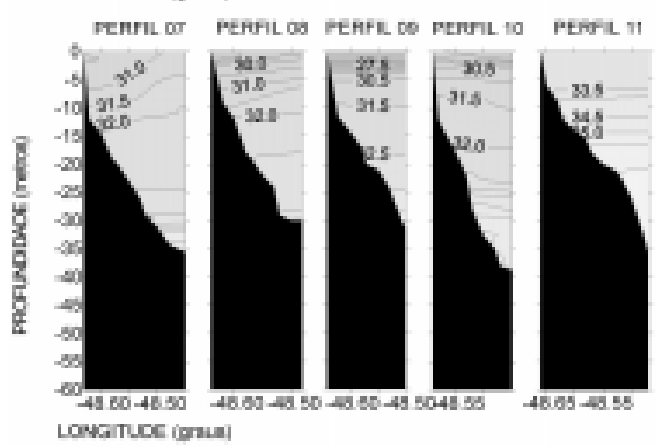

8 A 13 DE JULHO/1995
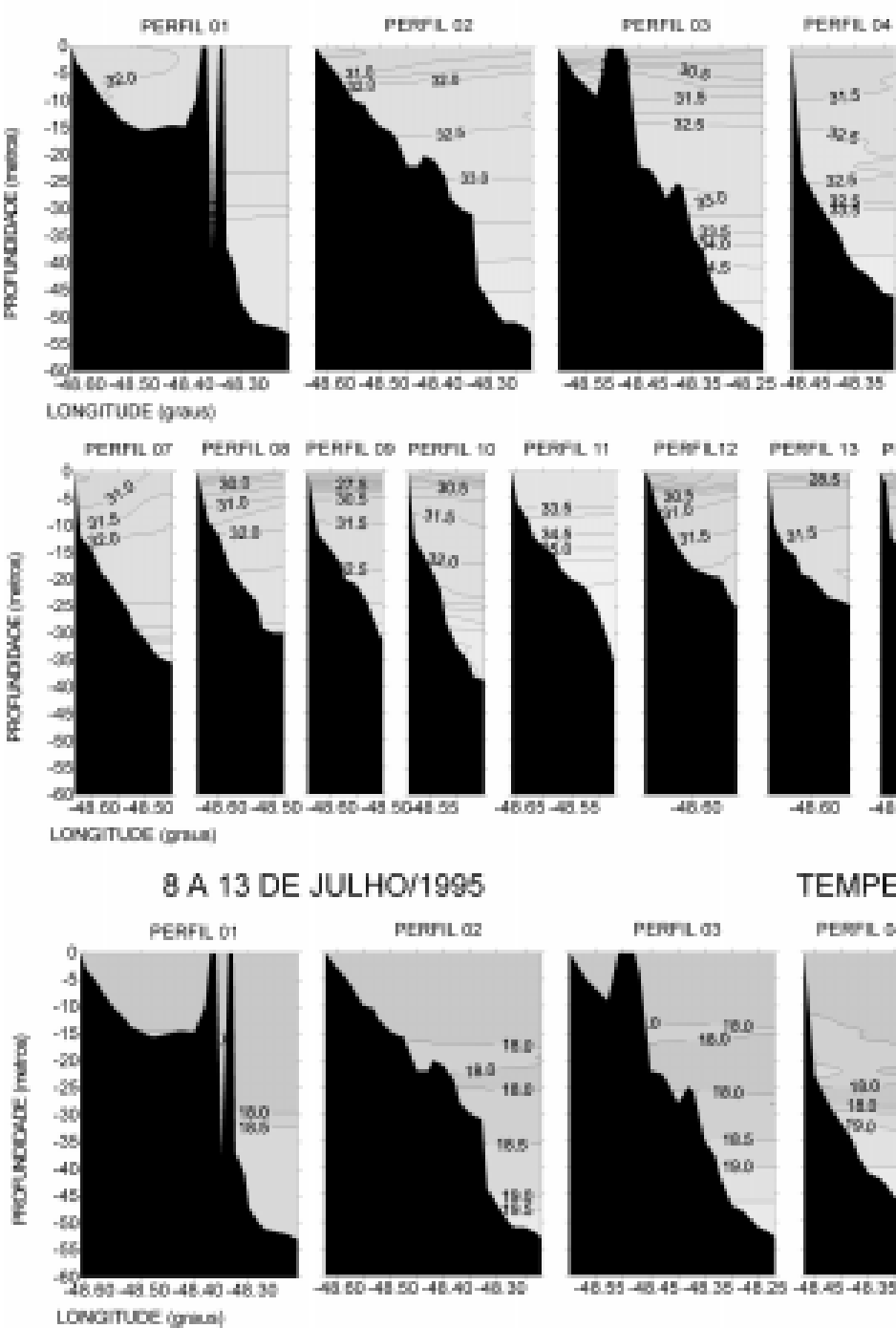

$-45.58-48.45-40.35-45.25-48.45-40.35$

PENLE12

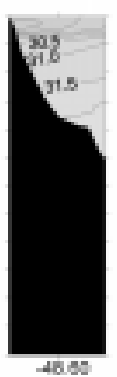

$-4805$

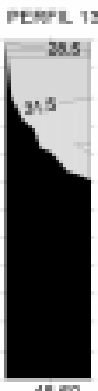

$-48.60$
SALINIDADE (PSU-78)

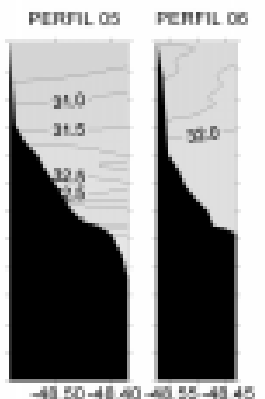

$-4150-4160-555-4145$

\section{TEMPERATURA (Oc)}
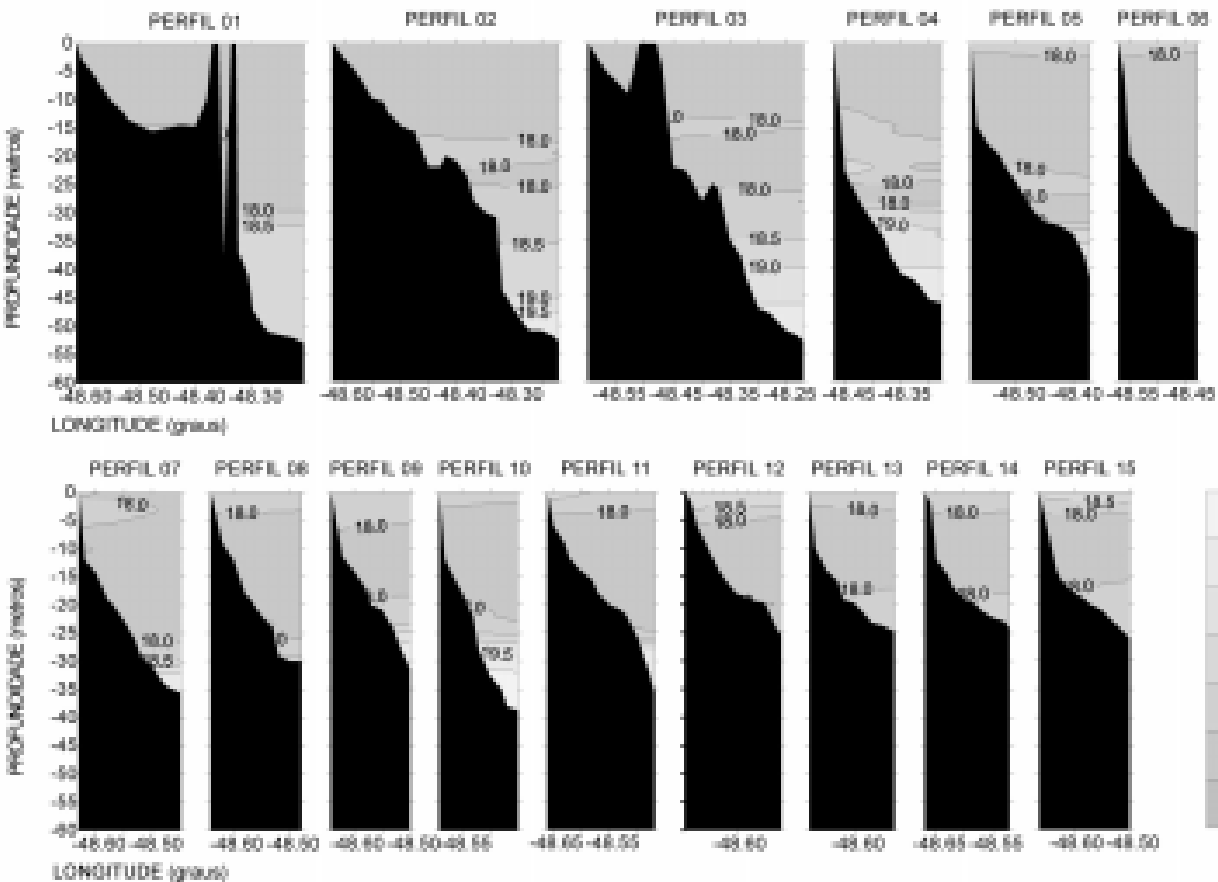

$-4960$

$-4960$

4655 - 55 - $4960-416$

Fig. 16 - Isohalinas (a) e Isotermas (b) dos perfis transversais do inverno de 95. 


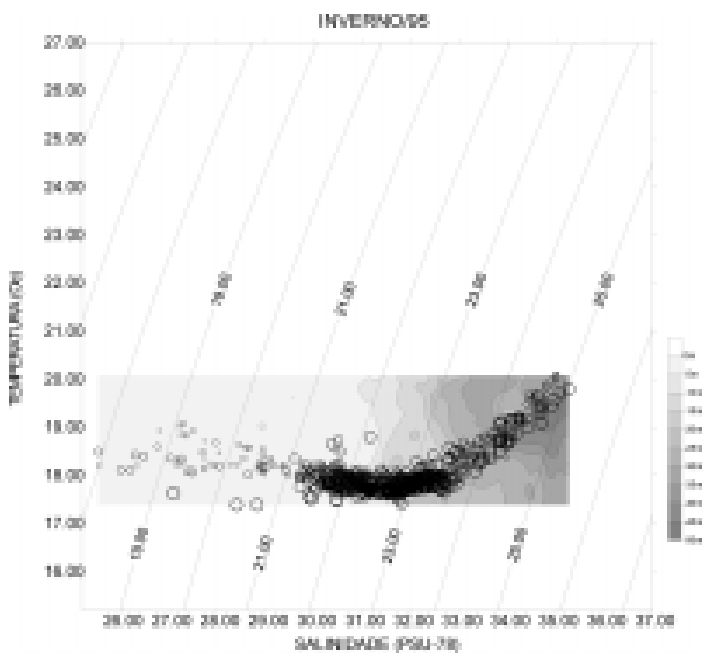

Rörig, L.R.; Kuroshima, K. N. Carvalho, J.L.B., Bellotto, V. R. \& Schettini, C.A.F. . 1997. Variação sazonal do fitoplâncton na área da Reserva Marinha Biológica do Arvoredo (Santa Catarina - Brasil) VII COLACMAR, Santos, Brasil. Resumos. 364-367pp

Schettini, C. A. F.; Carvalho, J. L. B. \& Jabor, P. M. 1996. Comparative hydrology and suspended matter distribution of four estuaries in Santa Catarina State Southern Brazil. Workshop on Comparative Studies of Temperate Coast Estuaries. Bahia Blanca, Argentina. Resumos. 29-32pp.

Fig. 17 - Diagrama TS do cruzeiro de inverno de 95.
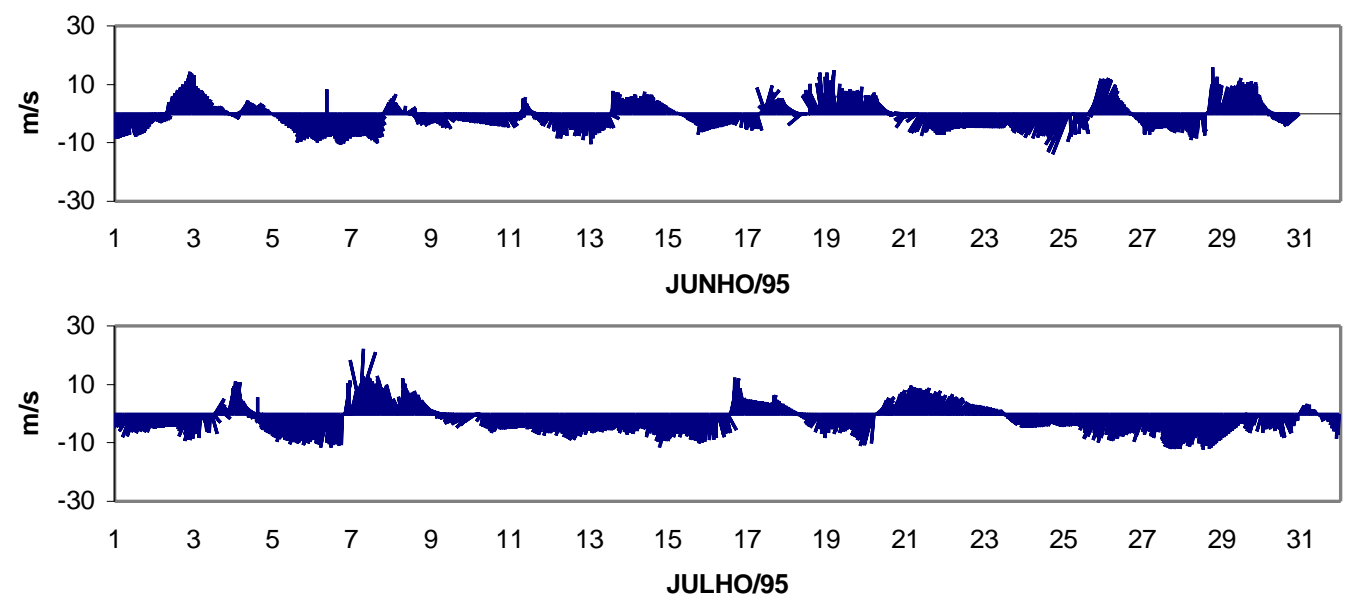

Fig. 18 - Série temporal de vento medido em P-XIV no mês do cruzeiro de inverno de 95 e no imediatamente anterior.

Catarina, Brasil. VII COLACMAR, Santos, Brasil. Resumos. 332-334pp

Rodrigues-Ribeiro, M.; Resgalla Jr., C; Carvalho, J. L. B. \& Speck, C. 1997. A Reserva Biológica Marinha do Arvoredo e adjacências pode ser considerada como área de desova e criação de recursos pelágicos? VII COLACMAR, Santos, Brasil. Resumos. 360-362pp 